\title{
Comparative Study of Solvent Extraction of Uranium with Alamine 336 and Aliquat 336: Application to the Uranium-Bearing Solutions of Niger Republic
}

\section{Chaibou Yacouba Abdoul-Rachid, PhD \\ Laouali Ibahim Salmana, PhD \\ Zanguina Adamou, Mc. \\ Natatou Ibrahim, Pr.}

Valorization of Materials, Water and Environment Laboratory,

Faculty of Sciences and Technologies (FAST),

Abdou Moumouni University, Niamey, Niger Republic

\section{Mamane Ibrahim}

Procedure-Quality Laboratory, Mining Company, Niger Republic

Doi: 10.19044/esj.2018.v14n9p76 URL:http://dx.doi.org/10.19044/esj.2018.v14n9p76

\begin{abstract}
This study focuses on the liquid-liquid extraction of uranium by anionic extractants of Alamine 336 and Aliquat 336. The objective of this study is to determine the parameters allowing the optimization of the extraction percentage of uranium, and other metals such as molybdenum, zirconium and vanadium. The extraction kinetics of uranium is achieved in 2 minutes. Sulfuric acid solutions are the media per excellence when using Alamine 336 as extractant. However,with Aliquat 336, it is orthophosphoric acid. Uranium is extracted at $99 \%$ in a single contact from the ratio: organic phase over aqueous phase $(\mathrm{O} / \mathrm{A})$ equals 1 . The extraction of uranium with Alamine 336 depends on the initial $\mathrm{pH}$ of the aqueous phase as well as the Alamine 336 concentration. Alamine 336 tends to release the uranium and the extracted zirconium until the $3^{\text {rd }}$ contact to the benefit of the molybdenum due to the natural occurrence of $\mathrm{Cl}^{-}, \mathrm{NO}_{3}^{-}$and $\mathrm{F}^{-}$ions in the uranium-bearing solutions which have the tendency of breaking the anion complexes. Vanadium, which is not extracted by Alamine 336 and Aliquat 336, can, in the hydrodynamic conditions of this work, be extracted by increasing the redox potential to $800 \mathrm{mV}$ and $\mathrm{pH} \geq 1$.
\end{abstract}

Keywords: Alamine 336, Aliquat 336, Liquid-liquid extraction, Molybdenum, Uranium 


\section{Introduction}

The hysteria some countries have over the use energy derived from uranium fission caused by industrial and nuclear accidents (Chernobyl (1986) and Fukushima (2011) and the desire to manage long-life radioactive waste drove some countries to question the use of this energy and to turn towards green power. However, the increasing demand for energy caused by a population growth on the rise, but also the arms race in which some military powers have thrown themselves into, make nuclear power to be the sole alternative (Evry \& Essonne, 2012; Services, 2011; Yuan et al., 2014; Mohapatra et al., 2014; Kumar,J.R.,et al., 2010; Ali, M. M., et al,. 2014). This alternative pushes to the research and development of new uranium deposits.

Thus, in uranium-producing countries where the uranium content of the ore is very weak, the treatment is done wet. This is the case for uranium companies of Niger Republic where the thickness of the deposits may vary between 1 and $10 \mathrm{~m}$ and an ore having between 0.2 and $0.6 \%$ of uranium content. These factories condensate and purify the uranium ore by hydrometallurgy. This process is a succession of physico-chemical operations, characterized by the dissolution of the metal and its elaboration from the solution. In Niger Republic, this process uses liquid-liquid extraction also known as solvent extraction as a purification method (Agnès M., 1985).

For this purpose, this process uses various molecules able to selectively extract the metals. The tertiary amines such as Alamine 336 widely used in the extraction of uranium by AMEX process (Kumar, J.R.., Kim, J.S., Lee, J.Y., Yoon, H.S., 2011; El-Nadi, Y.A., 2017), the phosphated extractants such as the trioctylphosphine oxide (TOPO), the di-2-ethylhexylphosphoric acid (D2EHPA or HDEHP) in synergy with tributylphosphate (TBP) through DAPEX process (El-Nadi, Y.A., 2017; Khanramaki, F., Shirani, A.S., Safdari, J., Torkaman, R., 2017; Kim, J.S., Han, K.S., Kim, S.J., Kim, S.D., Lee, J.Y., Han. C., Kumar, R.J., 2016) are widely used for the extraction, the separation and the purification various metals.

Generally confined to the uranium ore, zirconium, molybdenum and vanadium, due to the similarity in their chemicals properties, are found in varying proportions in the ores depending on the deposit in operation (Miguirditchian, M., Baron, P., Bisel I., Dinh, B., Sorel, C., 2011; Floreancig, A., Trescol, J., Siffert. B., 1981; Hawk. D.G., 1965; Lunt, D., Boshoff, P., Boylett,M., El-Ansary, Z., 2007); case depicted in Niger Republic. These metals represent impurities that penalize an industry wanting to preferentially valorize uranium.

It is in this regard that we focused on the liquid-liquid extraction of uranium by Alamine 336 and Aliquat 336 with the aim of studying their behavior on the uranium-bearing solutions resulting from the leaching of Niger Republic's uranium ore. 


\section{Material and Methods \\ The reactants}

This part of the work gives the extractants used as well as the diluents and added alcohol to avoid the formation of the $3^{\text {rd }}$ phase. Alamine 336 Fig.1. (a) with a flashpoint of $179{ }^{\circ} \mathrm{C}$ is provided by Cognis Corporation, and the 1Octanaminium, N-methyl-N,N-dioctyl-Bromide $\left(\mathrm{C}_{25} \mathrm{H}_{54} \mathrm{BrN}\right)$ or Aliquat 336 Fig.1. (b) provided by Molekula are prepared in various diluents, kerosene (TOTAL), toluene (Prolabo) and diisobutyl ketone (Prolabo) in the presence of isotridecanol (BASF) which has a flashpoint of $122.5^{\circ} \mathrm{C}$. The mixture of these reagents forms the organic phase.

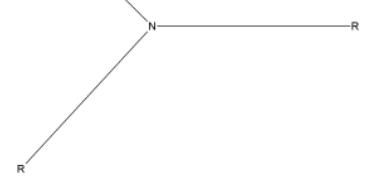

(a)

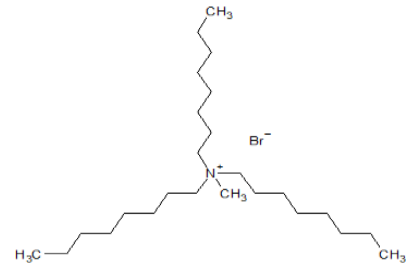

(b)

Fig.1. Chemical structures: (a) Alamine $336\left(\mathrm{R}=\mathrm{C}_{8}-\mathrm{C}_{10}\right)$ and (b) 1-Octanaminium,Nmethyl-N,N-dioctyl-,bromide $\left(\mathrm{C}_{25} \mathrm{H}_{54} \mathrm{BrN}\right)$ or Aliquat 336.

The synthetic uranium solutions are prepared at $(5 \mathrm{~g} / \mathrm{L})$ from the triuranium octoxide $\mathrm{U}_{3} \mathrm{O}_{8}(99.968 \% \pm 0.018 \mathrm{U})$ provided by $\mathrm{NBL}$ and the yellow cake $\mathrm{Na}_{2} \mathrm{U}_{2} \mathrm{O}_{7}(75 \% \mathrm{U}, \mathrm{Na} / \mathrm{U}<6 \%, \mathrm{Ca} / \mathrm{U}<0.15 \%, \mathrm{Mo} / \mathrm{U}<0.05 \%, \mathrm{Zr}$ $<0.06 \%, \mathrm{~V} / \mathrm{U} \approx 0 \%$ ) from companies of Niger Republic.

The metal salts $\left(\mathrm{NH}_{4}\right)_{6} \mathrm{Mo}_{7} .4 \mathrm{H}_{2} \mathrm{O}$ at $99 \%$ (MERK), $\mathrm{NH}_{4} \mathrm{VO}_{3} 99 \%$ (MERK) are prepared at $(5 \mathrm{~g} / \mathrm{L})$ in various minerals acids and the sodium chlorate $\left(\mathrm{NaClO}_{3}\right)$ used as an oxidant in vanadium extraction. All the solutions are prepared in demineralized water at $\mathrm{pH}=1$ and the experimental temperature is maintained at $30{ }^{\circ} \mathrm{C}$. Metals are attacked by the following minerals acids: $\mathrm{H}_{2} \mathrm{SO}_{4} 95 \%$ (VWR), $\mathrm{HNO}_{3} \quad 65 \%$ (VWR), $\mathrm{HCl} 37 \%$ (VWR), $\mathrm{H}_{3} \mathrm{PO}_{4} \quad 85 \%$ (VWR).

Table 1 provides the content of certain metals of the uranium-bearing solutions of Niger Republic's factories with free acidity $\left(\mathrm{H}^{+}\right)$of $22 \mathrm{~g} / \mathrm{L}$.

Table 1. Composition of uranium-bearing solutions samples

\begin{tabular}{lll}
\hline & Sample 1 & Sample 2 \\
\hline Uranium (mg/L) & 3698 & 1602 \\
\hline Molybdenum(mg/L) & 52 & 60 \\
\hline Vanadium (mg/L) & 2423 & 137.286 \\
\hline Zirconium (mg/L) & 20 & 54 \\
\hline Iron (mg/L) & 465 & 180 \\
\hline pH & 1 & 1 \\
\hline Redox Potential (mV) & 496 & 448 \\
\hline
\end{tabular}




\section{Extraction procedure}

The extraction process is done in $100 \mathrm{~mL}$ separatory funnels perfectly shaken. The shaking speed was set to 70 oscillations/min on an AGITELECbranded agitator. The $\mathrm{pH}$ is determined with a device branded Knick pH-Meter 766 Calimatic and the redox potential with a Mettler Toledo-branded device.

In a separatory funnel, $10 \mathrm{ml}$ of the aqueous phase containing the metal salt and $10 \mathrm{ml}$ of the organic phase containing the extractant are brought into contact and this for 2 minutes, time sufficient for the transfer of solute from one phase to the other until the determined equilibrium determined by a kinetic study is reached. At the end of the extraction, the two phases are separated by decantation. Vanadium and molybdenum are analyzed using a Varian AAFS240 atomic absorption spectrophotometer equipped with an acetylenenitrous oxide burner at the respective wavelengths 318 and $313 \mathrm{~nm}$. The determination of the metals of the aqueous phase was carried out directly after an adequate dilution. The uranium resulting from the nitric solution is extracted with trioctylphosphine oxide (TOPO) in a kerosene medium and is then assayed by colorimetry after the solvent has been added to the dibenzoylmethane reagent (DBM) and the zirconium is determined by the orange xylenol reagent in medium hydrochloric. Uranium and zirconium are analyzed by UV-Vis spectrophotometry with a Varian Cary $50 \mathrm{UV}$-Vis Spectrophotometer device at the respective wavelengths of 405 and $540 \mathrm{~nm}$.

The distribution coefficient (1) and the extraction percentage (2) are respectively determined by the relations:

$\mathrm{D}=\frac{[\mathbf{M}]_{\text {org }}}{[\mathbf{M}]_{\mathbf{a q}}} \quad(1) \quad \mathrm{E}(\%)=\frac{\mathbf{D}}{\mathbf{D}+\frac{\mathbf{V}_{\mathbf{a q}}}{\mathbf{V}_{\mathbf{o r g}}}} \times 100$

$[\mathrm{M}]_{\text {org }}=$ Metal concentration in the organic phase $(\mathrm{mg} / \mathrm{L})$

$[\mathrm{M}]_{\mathrm{aq}}=$ Metal concentration in the aqueous phase $(\mathrm{mg} / \mathrm{L})$

\section{Results and discussion \\ Extraction kinetics of uranium}

With a view to obtaining the contact time necessary to reach extraction equilibrium, the kinetic study of the transfer of the metal ions between the organic phase and the aqueous phase was carried out in two contacts. The aqueous phase has a uranium concentration of $3698 \mathrm{mg} / \mathrm{L}$ from uranium-bearing solution and $\mathrm{pH}=1$. The Alamine 336 concentration in the organic phase is of $0.1 \mathrm{M}$. The extraction is done at $30{ }^{\circ} \mathrm{C}$. The obtained results are displayed in Fig.2. According to these results, the extraction kinetics of uranium is fast. The peak obtained before two minutes reflects that the best time seen fit to reach equilibrium is 2 minutes. In literature, research done by (Zhu, Z., Pranolo, Y., Cheng, C. Y., 2016; Agrawal, A., Mishra, D., Sahu, K. K., 2016) also show that this time do not exceed 3 minutes. 


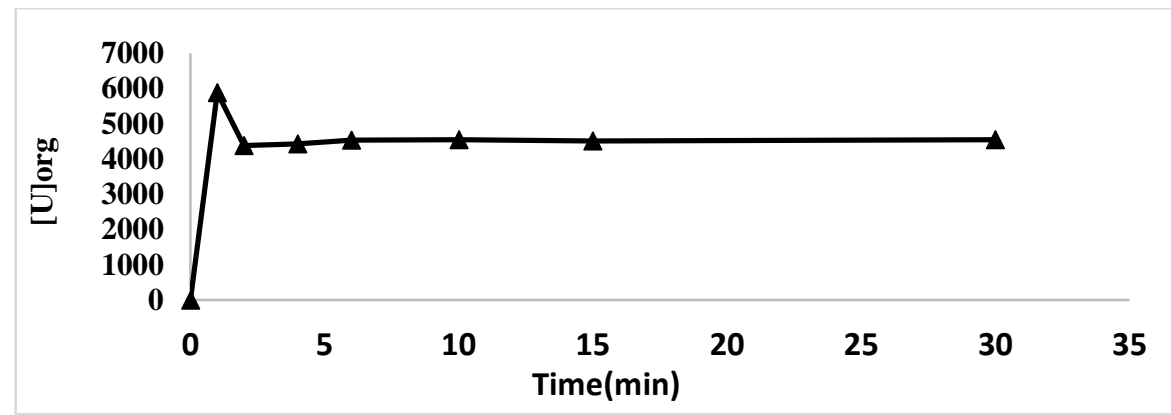

Fig.2. Extraction kinetics of uranium

\section{Effect of the etching solution}

Different mineral acids $\left(\mathrm{H}_{2} \mathrm{SO}_{4}, \mathrm{HNO}_{3}, \mathrm{HCl}, \mathrm{H}_{3} \mathrm{PO}_{4}\right)$ were used in order to determine the best solublization medium. The aqueous phase prepared form $\mathrm{Na}_{2} \mathrm{U}_{2} \mathrm{O}_{7}$ has a uranium concentration of $3 \mathrm{~g} / \mathrm{L}$. The extractants used are Alamine 336 and Aliquat 336 at $0.2 \mathrm{M}$. The pH is set at 1 and the redox potential at $628 \mathrm{mV}$. Fig. 3 shows the obtained results. For Alamine 336, the extractability sequence of uranium follows the order next off: $\mathrm{H}_{2} \mathrm{SO}_{4}>\mathrm{H}_{3} \mathrm{PO}_{4}$ $>\mathrm{HCl}>\mathrm{HNO}_{3}$. For Aliquat 336, the sequence follows the order: $\mathrm{H}_{3} \mathrm{PO}_{4}>\mathrm{HCl}$ $>\mathrm{HNO}_{3}>\mathrm{H}_{2} \mathrm{SO}_{4}$.

$E(\%)$
100
80
60
40
20
0

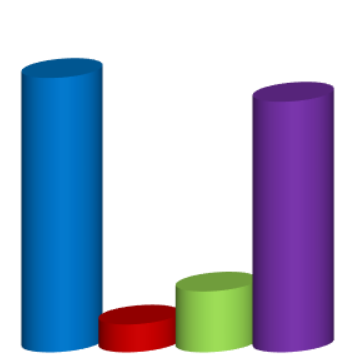

Alamine 336

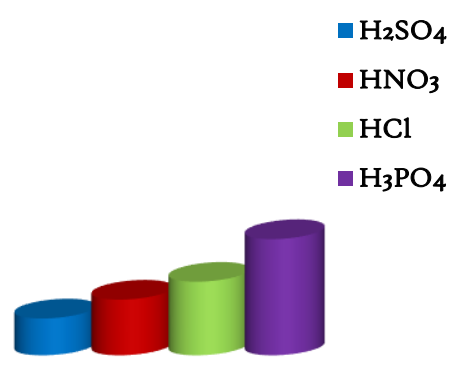

Aliquat 336

Fig.3. Effect of acid on the extraction of uranium by Alamine 336 and Aliquat 336

\section{Effect of solvent}

Kerosene, toluene and diisobutyl ketone (DIBK) were used on the extraction of uranium. The aqueous phase prepared from $\mathrm{Na}_{2} \mathrm{U}_{2} \mathrm{O}_{7}$ has a concentration of $3 \mathrm{~g} / \mathrm{L}$ in uranium. The organic phase has an Alamine 336 concentration of $0.2 \mathrm{M}$. The $\mathrm{pH}$ is set at 1 the redox potential at $628 \mathrm{mV}$. Fig.4. shows the obtained results. The extraction percentage of uranium grows according to the order: Toluene $>$ Kerosene $\approx$ DIBK. 


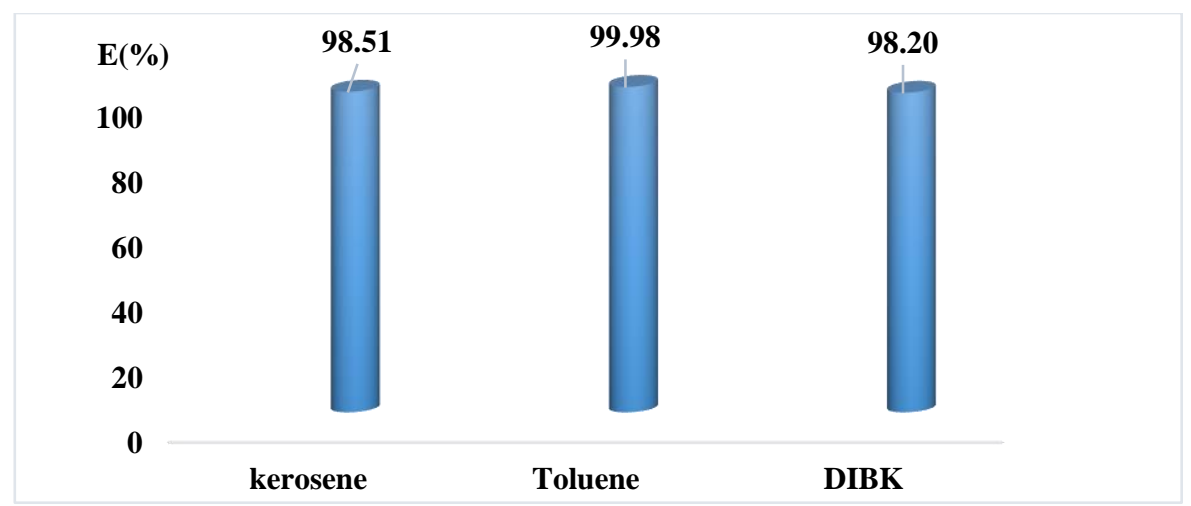

Fig.4. Effect of the solvent on the extraction of uranium by Alamine 336

\section{Effect of the ratio between the organic phase and the aqueous phase}

The aqueous phase prepared from $\mathrm{U}_{3} \mathrm{O}_{8}$ has a uranium concentration of $3 \mathrm{~g} / \mathrm{L}$ and $\mathrm{pH}=1$. The organic phase has an Alamine 336 concentration of 0.2 $\mathrm{M}$. The experimental temperature is maintained at $30{ }^{\circ} \mathrm{C}$. The effects of the variation of volume ratio of the two phases to the extraction efficiency were studied and illustrated on Fig.5. This work clearly shows that from a ratio O/A $=1$, we can retrieve at $99 \%$ the uranium contained in the aqueous phase with a single contact.

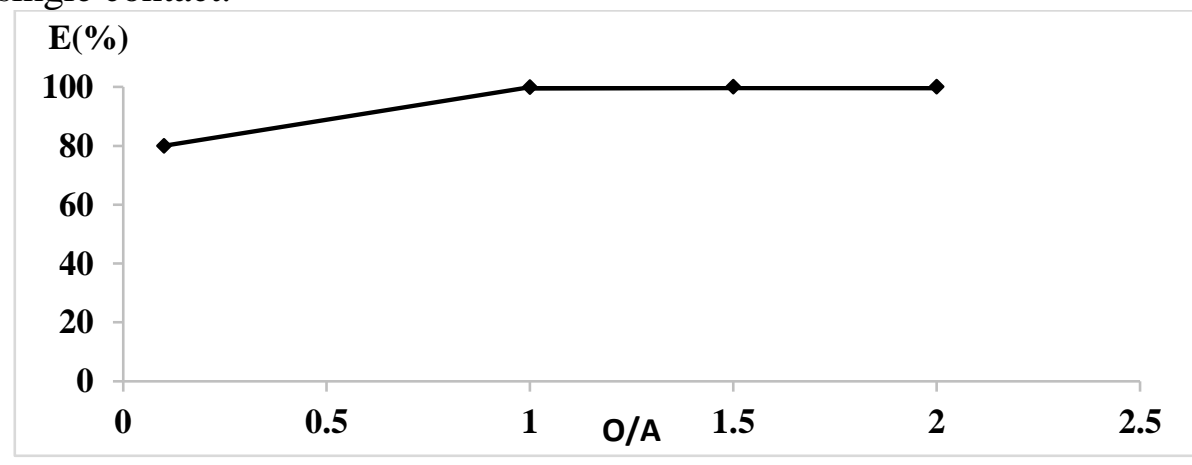

Fig.5. Extraction percentage of uranium as a function of the ratio of the organic phase and the aqueous phase

\section{Effect of the Alamine 336 concentration}

The uranium-bearing solutions in Niger Republic have a free acidity $\left(\mathrm{H}^{+}\right)$of $22 \mathrm{~g} / \mathrm{L}$. In order not to render the sulfate ion predominant in the medium and cause a drop in the extraction percentage, the Alamine 336 is contacted with a sulfuric acid solution according to the reaction (3):

$$
2\left(\mathrm{R}_{3} \mathrm{~N}\right)_{\text {org }}+\left(\mathrm{H}_{2} \mathrm{SO}_{4}\right)_{\mathrm{aq}} \quad \rightleftarrows\left[\left(\mathrm{R}_{3} \mathrm{NH}\right)_{2} \mathrm{SO}_{4}\right]_{\text {org }}
$$

It is a sulfatation reaction

The aqueous phase prepared from $\mathrm{U}_{3} \mathrm{O}_{8}$ has a uranium concentration of $5 \mathrm{~g} / \mathrm{L}$ and $\mathrm{pH}=1$. The Alamine 336 concentration in the organic phase varies from $10^{-3} \mathrm{M}$ to $0.2 \mathrm{M}$. The experimental temperature is maintained at $30^{\circ} \mathrm{C}$. 
During the extraction, the nature of the chemical species formed in the organic phase is characterized by the "slopes" method. This method is based on the determination of the values of the distribution coefficient (D) of metal ions by varying the initial $\mathrm{pH}$ of the aqueous phase and the concentration by extractant. Fig.6. shows the $\log \mathrm{D}$ as a function of the log [Alamine 336]. The correlation between the distribution coefficients logarithms and the Alamine 336 concentration shows a linearity which is expressed by the relation:

$\mathrm{D}=\left(\mathrm{K}\left[\mathrm{R}_{3} \mathrm{NH}\right]^{\mathrm{p}}\right)$ with a slope $(\mathrm{p})$ close to 2 . This correlation also shows that 2 molecules of Alamine 336 complex one mole of uranyl sulfate. Likewise, rising the concentration of Alamine 336 (from $10^{-3} \mathrm{M}$ to $0.2 \mathrm{M}$ ) increases the extraction percentage from $1 \%$ to $99 \%$.

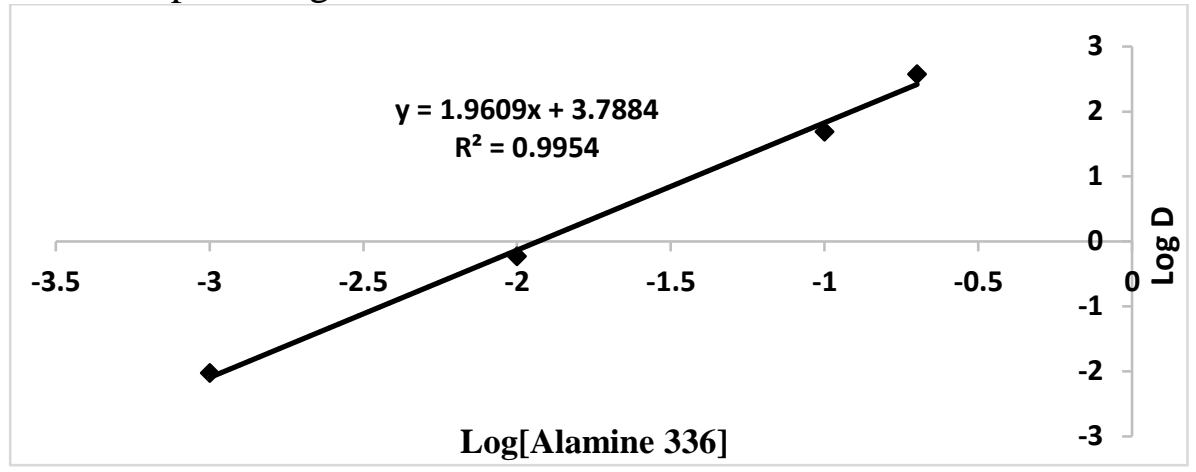

Fig.6. Graph logarithm of the distribution coefficient as a function of the logarithm of the Alamine 336

\section{Effect of the initial pH of the aqueous phase}

During the uranium extraction by the Alamine 336, we extract the uranium under its valence 6 corresponding to the cation of the uranyl $\mathrm{UO}_{2}^{2+}$ (Baron, P., Bernier, G., Hartmann, D., Laluc,C., Marbet, M., 2014) with the release of $\mathrm{SO}_{4}^{2-}$ ions reflected by the equation (4):

$$
2\left[\left(\mathrm{R}_{3} \mathrm{NH}\right)_{2} \mathrm{SO}_{4}\right]_{\text {org }}+\left[\mathrm{UO}_{2}\left(\mathrm{SO}_{4}\right)_{2}^{2-}\right]_{\mathrm{aq}} \rightleftarrows\left[\left(\mathrm{R}_{3} \mathrm{NH}\right)_{4} \mathrm{UO}_{2}\left(\mathrm{SO}_{4}\right)_{3}\right]_{\text {org }}+\left[\mathrm{SO}_{4}^{2-}\right]_{\mathrm{aq}}
$$

It is an anion exchange reaction.

To see the influence of the acid on this balance, various $\mathrm{pH}$ of the aqueous phase have been studied during the uranium extraction by Alamine 336. The aqueous phase prepared from $\mathrm{U}_{3} \mathrm{O}_{8}$ has a uranium concentration of 3 $\mathrm{g} / \mathrm{L}$ and $\mathrm{pH}=1$. The concentration of Alamine 336 in the organic phase is of $0.2 \mathrm{M}$. The experimental temperature is maintained at $30^{\circ} \mathrm{C}$. Fig.7. gives the obtained results. The increase in the $\mathrm{pH}$ toward 5 decreases the distribution coefficient, because from $\mathrm{pH}=2$ uranium tends to precipitate into its form $\mathrm{UO}_{2}(\mathrm{OH})_{2}$, this result is in agreements with that works (Bhargava, S.K., Rahul, R., Pownceby, M., Grocott, S., Ring, B., Tardio, J., Jones, L., 2015). The study 
of the logarithm of the distribution coefficient as a function of the $\mathrm{pH}$ variation between 1 to 5 shows a linearity with a slope of around -2 . This result states that 2 moles of $\mathrm{H}^{+}$ions are released for the uranyl sulfate to form and the decrease of the percentage of uranium extraction due to $\mathrm{pH}$ rise still justifies that extraction follows the mechanism of anion exchange extraction.

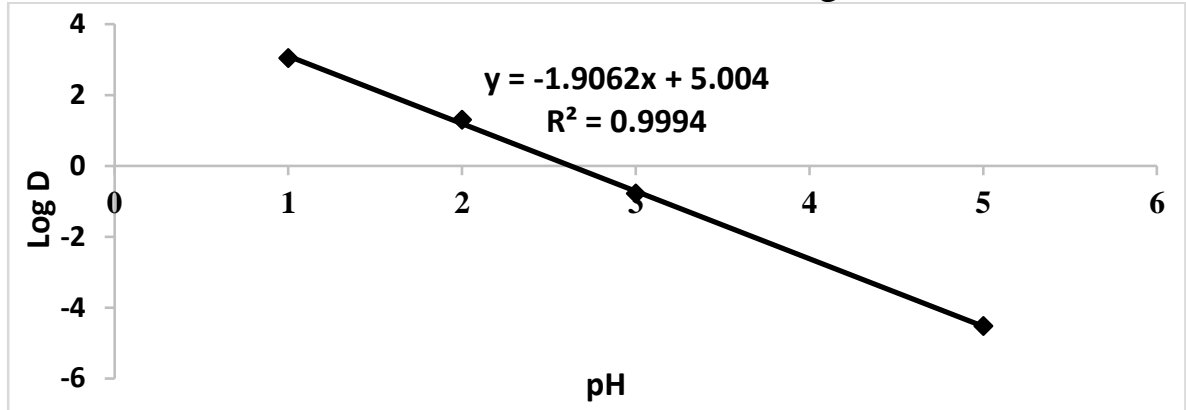

Fig.7. Graph logarithm of the distribution coefficient against the initial $\mathrm{pH}$ of the aqueous phase

It is clear from the earlier results Fig.6. and Fig.7., that the reaction of the uranium extraction by Alamine 336 in sulfuric medium is reflected by the relation (5), similar result with the literature (Avelar, E.C., Alvarenga, C. L. G., Resende, G. P. S., Morais, C. A., Mansur, M. B., 2017; Kumar, J. R., Kim, J. S., Lee, J. Y., \& Yoon, H. S., 2010; Schrötterová,D., Nekovář, P., Mrnka, M., 1992) confirm these results:

$$
\begin{aligned}
& \left.\left[\mathrm{UO}_{2}\left(\mathrm{SO}_{4}\right)_{2}^{2-}\right]_{\mathrm{aq}}+\left[\mathrm{x}\left(\mathrm{R}_{3} \mathrm{NH}\right)_{2} \mathrm{SO}_{4}\right)\right]_{\text {org }} \rightarrow\left[\mathrm{x}\left(\mathrm{R}_{3} \mathrm{~N}\right)_{2} \mathrm{UO}_{2}\left(\mathrm{SO}_{4}\right)_{2}^{2-}\right]_{\text {org }}+ \\
& {\left[\mathrm{xH}^{+}, \mathrm{SO}_{4}^{2-}\right]_{\mathrm{aq}}}
\end{aligned}
$$

Where Keq: equilibrium constant

$\mathrm{K}_{\mathrm{eq}}=\frac{\mathrm{D}\left[\boldsymbol{x H}^{+}\right]}{\left.\left[\mathbf{x}\left(\boldsymbol{R}_{3} \mathbf{N H}\right)_{2} \mathbf{S O}_{4}\right)\right]}$

$\mathrm{D}$ : distribution coefficient

$\mathrm{D}=\frac{\left[\mathrm{x}\left(\mathrm{R}_{3} \mathrm{~N}\right)_{2} \mathrm{UO}_{2}\left(\mathrm{SO}_{4}\right)_{2}^{2-}\right]_{\text {org }}}{\left[\mathrm{Uo}_{2}\left(\mathrm{So}_{4}\right)_{2}^{2-}\right]_{a q}}$

$\left.\log \mathrm{D}=\log \mathrm{K}_{\mathrm{eq}}+\log \left[\mathrm{x}\left(\mathrm{R}_{3} \mathrm{NH}\right)_{2} \mathrm{SO}_{4}\right)\right]-\log \left[\mathrm{xH}^{+}\right]$

According to the relation (6) the uranium extraction depends on the $\mathrm{pH}$ of the solution as well as the concentration of Alamine 336.

\section{Effect of the Alamine 336 /Aliquat 336 synergism in function of the number of contact}

Fig.8. shows the results obtained on the effect of the synergism coupled to the number of contact. The number of contact consists in maintaining a 
constant volume of the organic phase and varying the volume of the aqueous phase after every 2 minutes of agitation. The aqueous phase prepared from $\mathrm{Na}_{2} \mathrm{U}_{2} \mathrm{O}_{7}$ has uranium concentration of $3 \mathrm{~g} / \mathrm{L}$. The organic phase has $0.2 \mathrm{M}$ of Alamine 336 concentration and $0.1 \mathrm{M}$ of Aliquat 336 concentration. The $\mathrm{pH}$ is fixed to 1 and the redox potential to $628 \mathrm{mV}$. Until the $2^{\text {nd }}$ contact the Alamine 336 charges to $99 \%$ in uranium and after the percentage drops. The addition of the Aliquat 336 at $0.1 \mathrm{M}$ has no effect on the extraction percentage. Nevertheless, we notice a linear drop in the extraction percentage due to a competition between the two anionic extractants.

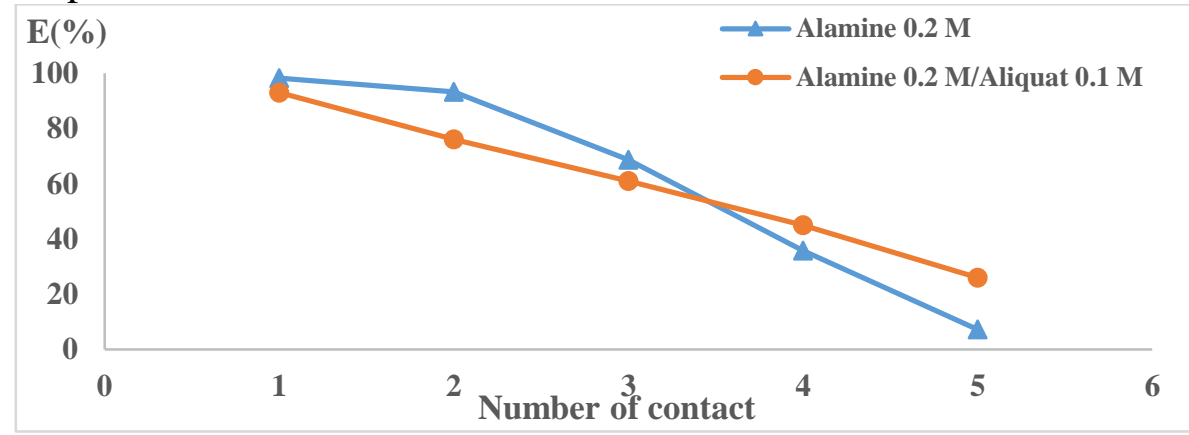

Fig.8. Extraction percentage of uranium as a function of the effect of the Alamine 336/Aliquat 336 synergism and the number of contact

\section{Effect of the number of contact}

The extraction was performed on uranium-bearing solutions of Niger Republic containing the following metals: uranium $=1602 \mathrm{mg} / \mathrm{L}$, molybdenum $=60 \mathrm{mg} / \mathrm{L}$, vanadium $=137.286 \mathrm{mg} / \mathrm{L}$, zirconium $=54 \mathrm{mg} / \mathrm{L}$, iron $=180 \mathrm{mg} / \mathrm{L}$, $\mathrm{pH}=1$, the redox potential is to $448 \mathrm{mV}$ and the organic phase has an Alamine 336 concentration of $0.15 \mathrm{M}$. The experimental temperature is maintained at 30 ${ }^{\circ} \mathrm{C}$. Fig.9. shows that for low levels of molybdenum, the Alamine 336 continues to charge to more than $85 \%$ in uranium until the $4^{\text {th }}$ contact with a molybdenum content of $27 \%$. After the $4^{\text {nd }}$ contact, the Alamine 336 tends not to load in uranium and molybdenum anymore.

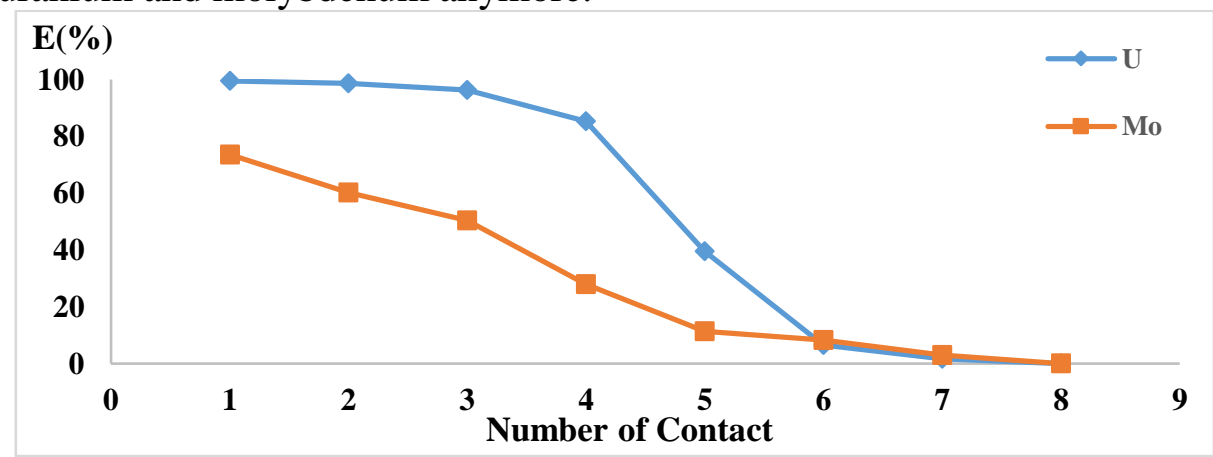

Fig.9. Extraction percentage of uranium and molybdenum as a function the number of contact 


\section{Effect of the molybdenum and vanadium concentration on the uranium of extraction by Alamine 336}

The molybdenum and vanadium contents in the uranium-bearing solution were raised respectively by the addition of $\left(\mathrm{NH}_{4}\right)_{6} \mathrm{Mo}_{7} .4 \mathrm{H}_{2} \mathrm{O}$ and $\mathrm{NH}_{4} \mathrm{VO}_{3}$. The new aqueous phase has the following contents: $\mathrm{U}=1602 \mathrm{mg} / \mathrm{L}$, $\mathrm{Mo}=1 \mathrm{~g} / \mathrm{L}, \mathrm{V}=1107 \mathrm{mg} / \mathrm{L}$ and $\mathrm{Zr}=54 \mathrm{mg} / \mathrm{L}, \mathrm{pH}=1$, the redox potential is at $448 \mathrm{mV}$ and the organic phase has an Alamine 336 concentration of $0.15 \mathrm{M}$. The experimental temperature is maintained at $30{ }^{\circ} \mathrm{C}$. Fig. 10 . shows the obtained results. The increase in the concentration of molybdenum also causes its extraction percentage to grow hence making the valorization of the uranium difficult. The Alamine 336 tends to release the uranium and the zirconium extracted until the $3^{\text {rd }}$ contact to the benefit of the molybdenum. This release seems to be caused by the natural presence of ions $\mathrm{Cl}^{-}, \mathrm{NO}_{3}^{-}, \mathrm{F}^{-}$which tend to break the anionic complexes. The extraction of vanadium is non-existent in these hydrodynamic conditions.

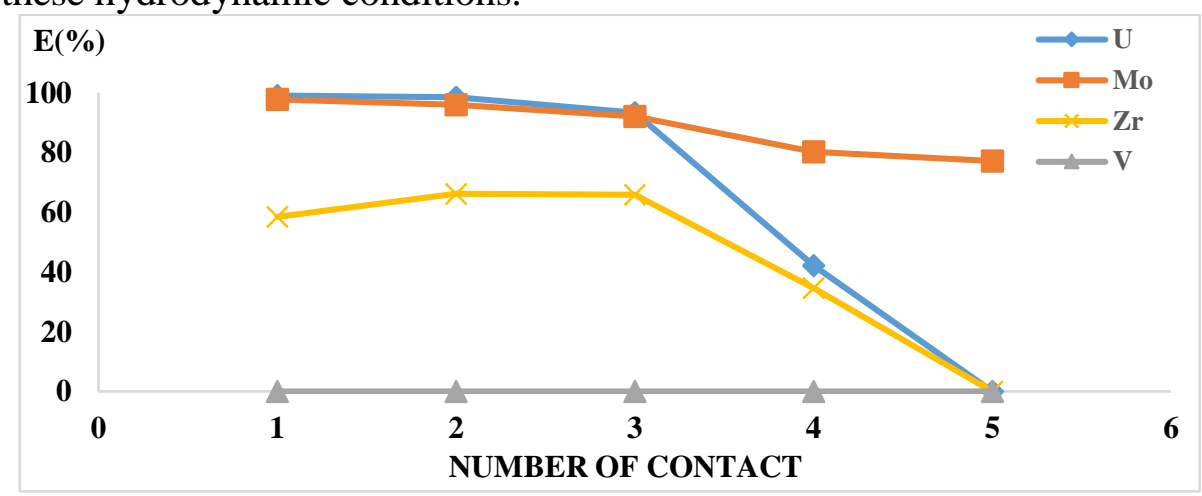

Fig.10. Extraction percentage of uranium, molybdenum, zirconium and vanadium by Alamine 336 as a function of the number of contact

\section{Effect of the formation of the $3^{\text {rd }}$ phase on the decantation}

Decantation is one among the important parameters in liquid-liquid extraction. Fig.11. shows: (A) synthetic solution containing only uranium at a concentration of $1 \mathrm{~g} / \mathrm{L}$ from $\mathrm{U}_{3} \mathrm{O}_{8}$ and $(\mathrm{B})$ uranium-bearing solutions. The $\mathrm{pH}=$ 1 , the redox potential is at $448 \mathrm{mV}$ for the aqueous phases and the organic phase has an Alamine 336 concentration of $0.2 \mathrm{M}$. The experimental temperature is maintained at $30{ }^{\circ} \mathrm{C}$. On Fig.11. (A) until the $5^{\text {th }}$ contact we get a perfect separation of the two phases while in (B) the solution loaded with several metals leads to the formation of a $3^{\text {rd }}$ phase making the decantation difficult. The formation of the $3^{\text {rd }}$ phase appears to be due to the presence of several metals in the solutions. 

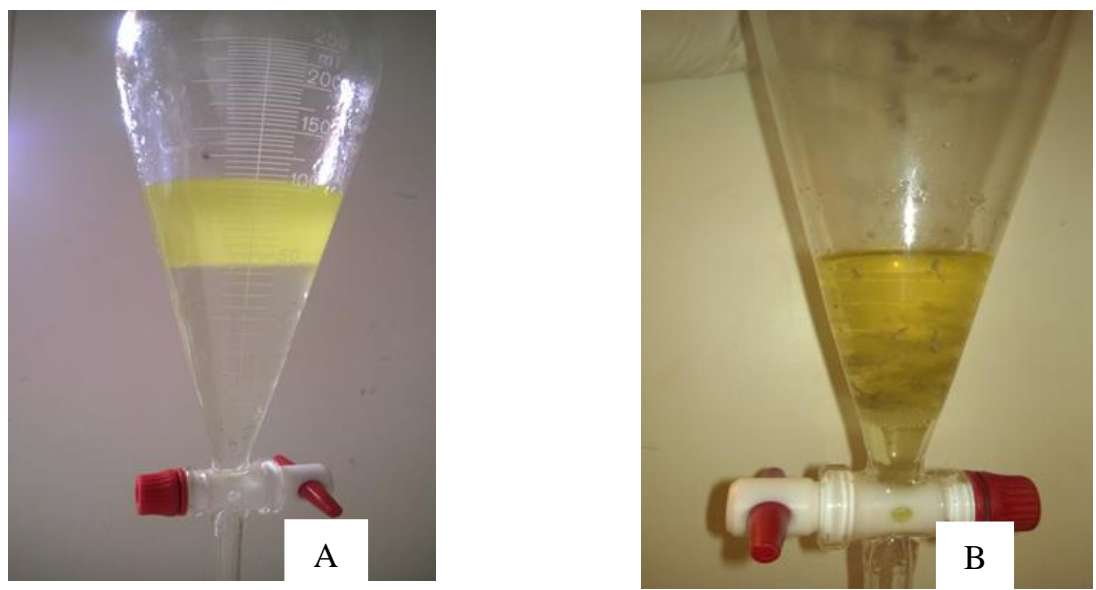

Fig.11. Formation of the $3^{\text {rd }}$ phase during the uranium extraction by Alamine 336

\section{Effect of the molybdenum and vanadium concentration on the uranium extraction by Aliquat 336}

The uranyl sulfate extraction by Aliquat 336 in a sulfuric medium (El Sayed, M. S., 2003) is described according to equation (7):

$4\left[\mathrm{R}_{3} \mathrm{~N}^{+} \mathrm{CH}_{3} \mathrm{Br}^{-}\right]_{\text {org }}+\left[\mathrm{UO}_{2}\left(\mathrm{SO}_{4}\right)_{3}^{4-}\right]_{\mathrm{aq}} \rightleftarrows\left[\left(\mathrm{R}_{3} \mathrm{NCH}_{3}\right)_{4} \mathrm{UO}_{2}\left(\mathrm{SO}_{4}\right)_{3}\right]_{\mathrm{org}}+4\left[\mathrm{Br}^{-}\right]_{\mathrm{aq}}$

In this study the contents of molybdenum and vanadium in the uraniumbearing solutions were raised respectively by the addition of $\left(\mathrm{NH}_{4}\right)_{6} \mathrm{Mo}_{7} .4 \mathrm{H}_{2} \mathrm{O}$ and $\mathrm{NH}_{4} \mathrm{VO}_{3}$. The new aqueous phase contains the following levels: $\mathrm{U}=1602$ $\mathrm{mg} / \mathrm{L}, \mathrm{Mo}=1 \mathrm{~g} / \mathrm{L}, \mathrm{V}=1107 \mathrm{mg} / \mathrm{L}$ and $\mathrm{Zr}=54 \mathrm{mg} / \mathrm{L}, \mathrm{pH}=1$, the redox potential is to $448 \mathrm{mV}$ and the organic phase has an Aliquat 336 concentration of $0.15 \mathrm{M}$. The experimental temperature is maintained at $30{ }^{\circ} \mathrm{C}$. Fig. 12 . shows the obtained results. Aliquat 336 extracts the molybdenum to $99 \%$ up to the $5^{\text {th }}$ contact, the zirconium concentration goes from $65 \%$ between the $1^{\text {st }}$ and $2^{\text {nd }}$ contact to $35 \%$ at the $5^{\text {th }}$ contact, as for the uranium the percentage goes from $20 \%$ at the 1 st contact to $5 \%$ at the $5^{\text {th }}$ contact, vanadium is not extracted either in these hydrodynamic conditions.

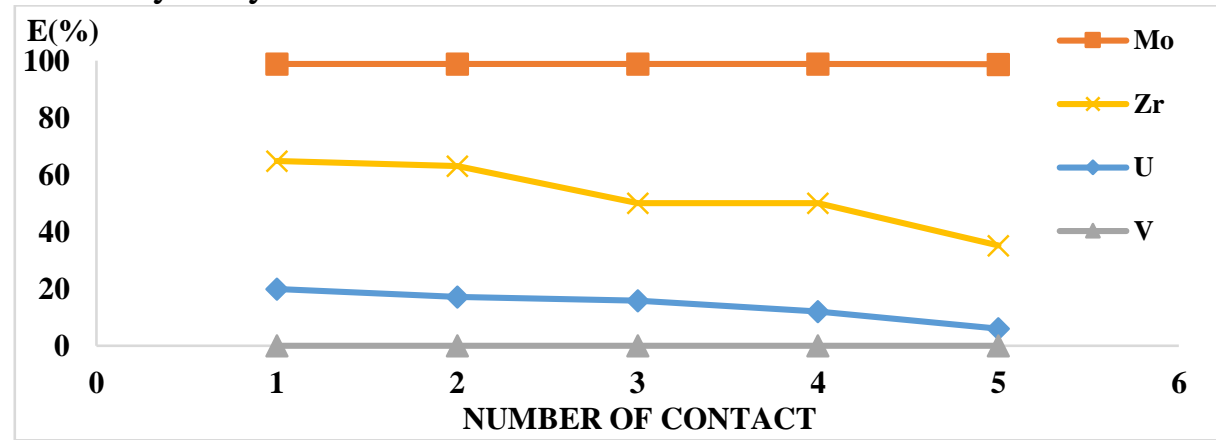

Fig.12. Extraction percentage of uranium, molybdenum, zirconium and vanadium by Aliquat 336 as a function of the number of contact 


\section{Effect of the pH on the uranium extraction by Aliquat 336}

In order to study the low rate of uranium extraction by Aliquat 336, the initial $\mathrm{pH}$ of the aqueous phase was varied. The aqueous phase prepared from $\mathrm{Na}_{2} \mathrm{U}_{2} \mathrm{O}_{7}$ has a uranium concentration of $3 \mathrm{~g} / \mathrm{L}$. The organic phase has an Alamine 336 concentration of $0.2 \mathrm{M}$. The redox potential is at $628 \mathrm{mV}$ and the experimental temperature is maintained at $30{ }^{\circ} \mathrm{C}$. Fig. 13 . shows the obtained results. Aliquat 336 extracts very weakly the Uranium with low $\mathrm{pH}$ and the more we tend toward high $\mathrm{pH}$, the more we achieve efficiencies reaching $99 \%$. However, at these $\mathrm{pH}$ uranium tends to precipitate in the form of $\mathrm{UO}_{2}(\mathrm{OH})_{2}$ with redox potential of $628 \mathrm{mV}$.

$E(\%)$
100
80
60
40
20
0

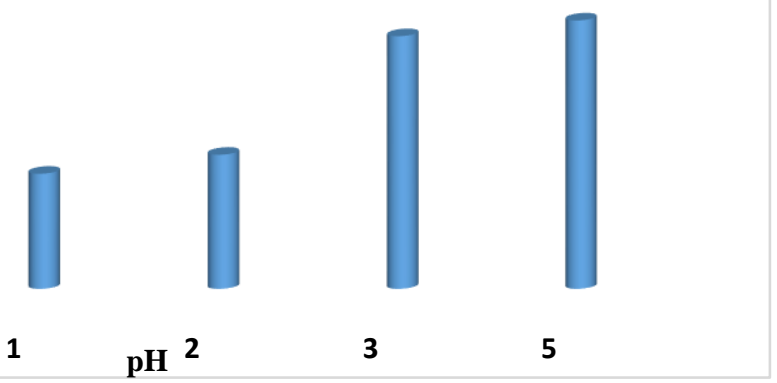

Fig.13. Extraction percentage of uranium by Aliquat 336 as a function of the $\mathrm{pH}$

\section{Effect of the redox potential on the vanadium extraction}

Vanadium in an aqueous solution shows different speciations which make the study of its complexes difficult. However at $\mathrm{pH}<2$ values, vanadium comes out mainly in its cationic form $\mathrm{VO}_{2}^{+}$(Olazabal, M. A., Orive, M. M., Fernandez, L. A., Madariaga, J. M., 1992; Sahu, K. K., Agrawal, A., Mishra, D., 2013; Nayl, A. A., Aly, H. F.. 2015; Hossein, M., Beiranvand, B., Ghorbanian, S. A., Mallah, M. H., 2014).In a sulfuric medium, according to the work (Yang, X., Zhang, Y., Bao, S., 2016; Chagnes, A., Rager, M., Courtaud, B., Thiry, J., Cote, G,. 2010) vanadium is in its $\mathrm{VO}_{2} \mathrm{SO}_{4}^{-}$form whose extraction mechanisms by Alamine 336 and Aliquat 336 translate respectively by equations (8) and (9):

$$
\begin{aligned}
& {\left[2 \mathrm{VO}_{2} \mathrm{SO}_{4}^{-}\right]_{\mathrm{aq}}+\left[2\left(\mathrm{R}_{3} \mathrm{NH}^{+}\right)\left(\mathrm{SO}_{4}\right)^{2-}\right]_{\mathrm{org}} \leftrightarrows 2\left[\left(\mathrm{R}_{3} \mathrm{NH}\right)^{+}\left(\mathrm{VO}_{2} \mathrm{SO}_{4}\right)^{-}\right]_{\mathrm{org}}+\left[\mathrm{SO}_{4}^{2-}\right]_{\mathrm{aq}}} \\
& {\left[\mathrm{VO}_{2}^{+}\right]_{\mathrm{aq}}+\left[\mathrm{H}_{2} \mathrm{SO}_{4}\right]_{\mathrm{aq}}+\left[\left(\mathrm{R}_{3} \mathrm{NCH}_{3}{ }^{+} \mathrm{Br}^{-}\right)\right]_{\mathrm{org}} \leftrightarrows\left[\left(\mathrm{VO}_{2} \mathrm{SO}_{4}\right) \mathrm{R}_{3} N C \mathrm{H}_{3}\right]_{\mathrm{org}}+2\left[\mathrm{H}^{+}\right]_{\mathrm{aq}}} \\
& +\left[B r^{-}\right]_{\mathrm{aq}}
\end{aligned}
$$

In order to study the non-extractability of vanadium by Alamine 336 and Aliquat 336, the variation of the redox potential was tested on a synthetic solution titrating at $5 \mathrm{~g} / \mathrm{L}$ from $\mathrm{NH}_{4} \mathrm{VO}_{3}$. The organic phase has $0.2 \mathrm{M}$ of concentration in Alamine 336 and in Aliquat 336 respectively. The initial redox potential fixed at $826 \mathrm{mV}$, the $\mathrm{pH}$ is fixed at 1 . The experimental temperature is maintained at $30{ }^{\circ} \mathrm{C}$. Fig. 14 . gives the obtained results. The increase in the redox 
potential causes to the extraction percentage of uranium to increase to $30 \%$ for the Alamine 336 and $16 \%$ for the Aliquat 336.

$$
\begin{array}{r}
\text { E(\%) } \\
100 \\
80 \\
60 \\
40 \\
20 \\
0
\end{array}
$$
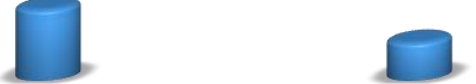

Alamine 336

Aliquat 336

Fig.14. Extraction percentage of vanadium by Alamine 336 and Aliquat 336

\section{Extraction of vanadium obtained from the uranium-bearing solutions with high redox potentials}

The redox potential of the uranium-bearing solutions of Niger Republic was raised by the addition of the $\mathrm{NaClO}_{3}$, the aqueous medium is initially at potentials between $448-500 \mathrm{mV}$, the aqueous phase has concentrations of 3698 $\mathrm{mg} / \mathrm{L}$ in uranium and $2423 \mathrm{mg} / \mathrm{L}$ in vanadium. The organic phase has an Alamine 336 concentration of $0.1 \mathrm{M}$. Fig. 15 . shows the obtained results. The extraction percentage of vanadium is $0 \%$ between $(448-500 \mathrm{mV})$, at this potential a large part of the vanadium is in the +4 oxidation state. However, this form of vanadium is non-extractable by tertiary amines (Floh (Miss), B., Abrao, A., Calmon Costa, E., 1971). That is why the reoxidation according to equation (10) of iron (II) naturally present in the environment (from the gangue) by the $\mathrm{NaClO}_{3}$ made it possible to oxidize the vanadium. The oxidation of $\mathrm{V}(\mathrm{IV})$ to $\mathrm{V}(\mathrm{V})$ has allowed to increase the extraction percentage of vanadium from $0 \%$ to $15 \%$. Likewise, his increase simultaneously leads to the drop in the extraction percentage of uranium.

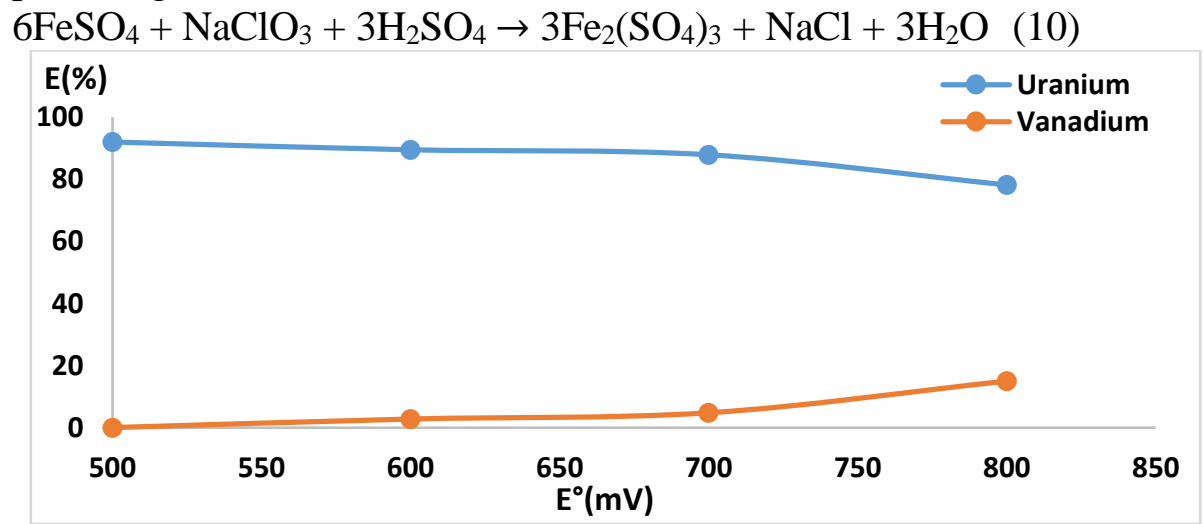

Fig.15. Extraction percentage of uranium and vanadium by Alamine 336 


\section{Conclusion}

Alamine 336 and Aliquat 336 were used on the uranium extraction of synthetic solutions as well as uranium-bearing solutions coming from two major mining companies Niger Republic. From this work, it appears that the kinetics of extraction is reached in 2 minutes with an extraction percentage reaching the $99 \%$ level from a ratio $\mathrm{O} / \mathrm{A}=1$. The best etching medium for Alamine 336 obeys the following extractability sequence of uranium: $\mathrm{H}_{2} \mathrm{SO}_{4}>\mathrm{H}_{3} \mathrm{PO}_{4}>\mathrm{HCl}$ $>\mathrm{HNO}_{3}$. Aliquat 336, the sequence follows the order $\mathrm{H}_{3} \mathrm{PO}_{4}>\mathrm{HCl}>\mathrm{HNO}_{3}>$ $\mathrm{H}_{2} \mathrm{SO}_{4}$.

Toluene, kerosene and diisobutyl ketone (DIBK) show the same behavior towards the uranium extraction.

The extraction by Alamine 336 follows the extraction mechanism by anionic exchange. The distribution coefficient rises with the increase in the Alamine 336 concentration and drops at higher $\mathrm{pH}$ levels. Due to the natural presence of ions such as $\mathrm{Cl}^{-}, \mathrm{NO}_{3}^{-}, \mathrm{F}^{-}$in the uranium-bearing solutions, the Alamine 336 tends to release uranium and zirconium loaded at the $3^{\text {rd }}$ contact to reach $0 \%$ at the $5^{\text {th }}$ contact to the benefit of the molybdenum.

By varying the redox potential and the $\mathrm{pH}$, vanadium can be extracted from the uranium-bearing solutions at $30 \%$ and $15 \%$ respectively for Alamine 336 and Aliquat 336 based on the number of contact.

\section{References:}

1. Agnès, M. (1985). Processes of Uranium Extraction in Sulfuric Medium by Emulsified Liquid Membranes. A Thesis submitted in accordance with the requirements of the doctor-engineer degree. E.N.S.C Lille.

2. Agrawal, A., Mishra, D., Sahu, K. K.(2016). Comparative performance assessment of solvents for the extraction of $\mathrm{H}_{2} \mathrm{SO}_{4}$ from spent electrolytic bleed stream of copper industry. Journal of Molecular Liquids. 220, pp. 82-91.

http://dx.doi.org/10.1016/j.molliq.2016.04.050

3. Ali, M. M., Taha M. H., Killa, H. M., Abd El Wanees S., El-Maadawy, M. M. (2014).Synergistic extraction of uranium from acidic sulfate leach liquor using D2EHPA mixed with TOPO. Journal of Radioanalytical and Nuclear Chemistry. 300(3), pp. 963-967. http://dx.doi.org/10.1007/s10967-014-3094-1

4. Avelar, E.C., Alvarenga, C. L. G., Resende, G. P. S., Morais, C. A.,

5. Mansur, M. B.(2017). Modeling of the solvent extraction equilibrium of Uranium (VI) Sulfate with Alamine 336. 34(1), pp. 355-362. http://dx.doi.org/10.1590/0104-6632.20170341s20150301

6. Baron, P.,Bernier, G., Hartmann, D., LALUC,C., MARBET, M.,(2014). Use of compounds comprising amide and phosphonate functions for extracting uranium(VI) from aqueous solutions of sulphuric acid, 
resulting in particular from sulphuric acid leaching of uranium comprising-ores.GooglePatents.

http://www.google.com/patents/WO2014139869A1?cl=en

7. Bhargava, S.K., Rahul, R., Pownceby, M., Grocott, S., Ring, B., Tardio, J.,Jones, L. (2015). A review of acid leaching of uraninite. Hydrometallurgy.151,pp.10-24. http://dx.doi.org/10.1016/j.hydromet.2014.10.015

8. Chagnes, A., Rager, M., Courtaud, B., Thiry, J., Cote, G.(2010). Hydrometallurgy Speciation of vanadium (V) extracted from acidic sulfate media by trioctylamine in $\mathrm{n}$-dodecane modi fi ed with 1 tridecanol.Hydrometallurgy.104(1),pp.20-24.

http://dx.doi.org/10.1016/j.hydromet.2010.04.004

9. Coralie, G. (2012). Influence of the environment on the alteration of the $\mathrm{UO}_{2}$ matrix of Irradiated fuel in storage situation. A thesis submitted in accordance with the requirements of the doctor's degree. pp. 25. Evry Val d'Essonne University.

10. El-Nadi, Y. A.(2017). Solvent Extraction and Its Applications on Ore Processing and Recovery of Metals: Classical Approach. Separation and Purification Reviews. 46(3), pp. 195-215. http://dx.doi.org/10.1080/15422119.2016.1240085

11. El Sayed, M. S.(2003). Uranium extraction from gattar sulfate leach liquor using aliquat-336 in a liquid emulsion membrane process. Hydrometallurgy.68(1-3), pp. 51-56. http://dx.doi.org/10.1016/S0304-386X(02)00159-7

12. Floh (Miss), B., Abrao, A., Calmon Costa, E. (1971). Amine extraction of uranium, molybdenum and vanadium from acid leach liquors (IAEASM-135/18).Symposium on the recovery of Uranium. pp. 267-285. www.iaea.org/inis/collection/NCLCollectionStore/ Public/02/008/200 8803.pdf

13. Floreancig,A., Trescol, J., Siffert, B. (1981). Reduction of organic solvent losses in hydrometallurgy. Google Patents. http://www.google.com/patents/WO1981001577A1?cl=en

14. Gordon, M. (2012). Environmental Aspects of Uranium Projects."Alta Uranium Conference. pp.178-196. http://www.altanet.com.au

15. Hawk, D.G.(1965). Extraction of metal values from acid solutions. Google Patents. https://www.google.ch/patents/US3223476

16. Hossein, M., Beiranvand, B., Ghorbanian, S. A., Mallah, M. H.(2014). Recovery of Vanadium from sulfuric acid medium by micro extraction by tri-C8-C10 - alkyl (Amines ). International Journal of Innovative Science, Engineering \& Technology. 1(9), pp. 589-593.www.ijiset.com

17. Khanramaki, F., Shirani, A. S., Safdari ,J., Torkaman, R.(2017). Equilibrium and kinetics of uranium(VI) extraction from a sulfate leach 
liquor solution by Alamine 336 using single drop technique. Chemical Engineering Research and Design. 125(6), pp.181-189. http://dx.doi.org/10.1016/j.cherd.2017.07.026

18. Kim, J.S., Han, K.S., Kim, S.J., Kim, S.D., Lee, J.Y., Han, C., ～Kumar, R.J.(2016).Synergistic extraction of uranium from Korean black shale ore leach liquors using amine with phosphorous based extractant system. Journal of Radioanalytical and Nuclear Chemistry. 307(2), pp. 843-854.http://dx.doi.org/10.1007/s10967-015-4327-7

19. Kumar, J. R., Kim, J. S., Lee, J. Y., Yoon, H. S. (2010). Solvent extraction of uranium (VI) and separation of vanadium (V) from sulfate solutions using Alamine 336. Journal of Radioanalytical and Nuclear Chemistry. 285(2), pp. 301-308. http://dx.doi.org/10.1007/s10967-010$\underline{0552-2}$

20. Kumar, J. R., Kim, J. S., Lee, J.Y., Yoon, H. S.(2011). A brief review on solvent extraction of uranium from acidic solutions. Separation and Purification Reviews.40(2), pp.77-125. http://dx.doi.org/10.1080/15422119.2010.549760

21. Lunt, D., Boshoff, P., Boylett,M., El-Ansary, Z.(2007).Uranium extraction: The key process drivers.Journal of the Southern African Institute of Mining and Metallurgy.107(7), pp. 419-426.

22. Miguirditchian, M., Baron, P., Bisel, I., Dinh, B., Sorel, C., Bertin, J.(2011). Liquid/liquid extraction method for purifying uranium from nitric acid dissolution of natural uranium concentrate. Google Patents. https://www.google.com/patents/CA2785001A1?cl=en

23. Mohapatra, P. K., Raut, D. R., Sengupta, A.(2014). Extraction of uranyl ion from nitric acid medium using solvent containing TOPO and its mixture with D2EHPA in room temperature ionic liquids.

Separation and Purification Technology.133,pp.69-75. http://dx.doi.org/10.1016/j.seppur.2014.06.033

24. Nayl, A. A., Aly, H. F.(2015) .Solvent extraction of V(V) and Cr(III) from acidic leach liquors of ilmenite using Aliquat 336. Transactions of Nonferrous Metals Society of China 25(12), pp. 4183-4191. http://dx.doi.org/10.1016/S1003-6326(15)64021-3

25. Olazabal, M. A., Orive, M. M., Fernandez, L. A., Madariaga, J. M.(1992). Selective extraction of vanadium (v) from solutions containing molybdenum (vi) by ammonium salts dissolved in toluene.Solvent Extraction and Ion Exchange. 10(4), pp. 623-635. http://dx.doi.org/10.1080/07366299208918125

26. Sahu, K. K., Agrawal, A., Mishra, D.(2013). Hazardous waste to materials: Recovery of molybdenum and vanadium from acidic leach liquor of spent hydroprocessing catalyst using alamine 308 .

Journal of Environmental Management. 125, pp. 68-73. 
http://dx.doi.org/10.1016/j.jenvman.2013.03.032

27. Schrötterová,D., Nekovár, P., Mrnka, M. (1992). Extractive Separation of Uranium and Zirconium Sulfates By Amines.Solvent Extraction and Ion-Exchange.10(2),pp.231-241.

http://www.tandfonline.com/doi/abs/10.1080/07366299208918102

28. Yuan, L., Sun, M., Liao, X., Zhao,Y., Chai, Z., Shi, W.(2014). Solvent extraction of $\mathrm{U}(\mathrm{VI})$ by trioctylphosphine oxide using a roomtemperature ionic liquid. Science China Chemistry. 57(11), pp. 14321438. http://dx.doi.org/10.1007/s11426-014-5194-8

29. Yang, X., Zhang, Y., Bao, S.(2016).Separation and recovery of sulfuric acid from acidic vanadium leaching solution of stone coal via solvent extraction. Journal of Environmental Chemical Engineering. 4(1), pp. 1399-1405. http://dx.doi.org/10.1016/j.jece.2015.11.038

30. Zhu, Z., Pranolo, Y., Cheng, C. Y.(2016). Uranium recovery from strong Acidic solutions by solvent extraction with Cyanex 923 and a modifier.Minerals-Engineering.89,pp.77-83.

http://dx.doi.org/10.1016/j.mineng.2016.01.016 